\title{
Local Leisure Sports Tourism Resources Development Path Research in the Background of Industry Integration-Take Qichun Country of Hubei Province as an Example
}

\author{
Bing ZHANG*, Qian YANG, Xiao HONG \\ Institute of Physical Education, Huanggang Normal University, Huangzhou 438000, HuBei, China \\ tiyuxi@qq.com
}

\begin{abstract}
With the development of world economy and the improvement of people's living standards, tourism has become an important human lifestyle in modern society, sports tourism as an important part in modern tourism, is a new industry featuring as tourism and sports that generated by crossing and integration of sports and tourism. The paper applies document literature, questionnaire survey, field visiting, logical analysis and other research methods, on the basis of fully grasping formers' research results, discusses theories and practical problems that Hubei province's Qichun country sports tourism development gets involve. According to Qichun country sports tourism resources development current situation, it conducts comprehensive analysis of sports tourism resources development, focuses on studying Qichun country current sports tourism resources reproducible development, and meanwhile excavates potential sports tourism resources, sets up big sports tourism ideas to beneficial to people's physical and psychological health, and strives for providing new thoughts for Qichun country sports tourism resources development. Research result is that Hubei province's Qichun country owns rich tourism resources and has unique features. However, "small", "scattering", "weak", "poor" and other serious problems prevail in sports tourism resources development, some resources are restricted by policies, economy and other conditions that lead to sports tourism product to lack of attraction, enterprises aftereffects and sustainable development capacity. Development countermeasures are as product optimization, reasonable allocation; resources integration, attraction improvement; channel diversified, capital introduction; features standing out, brands building and so on.
\end{abstract}

Keywords: Sports Tourism; National Fitness; Industry Integration; Leisure Sports

\section{INTRODUCTION}

As early as 1857 , Britain appeared mountaineering club in Europe, but sports tourism development in real sense was after the mid-term of 20th century. In recent years, its development was particularly fast, world sports tourism market has increased by 1300\% from 1967 to 1989 (WANG Ju-hai 2012). In Asia, sports tourism development also started to attract attentions, Japan, South Korea and other countries sports tourism that featured as ski was very lively (YAN Shuren 2012). With people's living standards improves, tourism rapidly develops, sports tourism also shows good development trend, massive participation positivity also appears unprecedented situation. Due to combination between sports and tourism, it better meets the demands of people's fitness and entertainment, which attracts eyes of domestic and international tourists (TAN et al. 2002). And sports tourism as an interdisciplinary of sports industry and tourism, it brings people kind of global fashion activities with its unique fitness, entertainment, relaxation, communication and other features (Zhang Bing, Shi Zhengkai, Yu Libin, Jiang Weiqi, Tian Miao, Liu, Lu, 2014). It is reported that since sports tourism has emerged in China in 1994, it has always increased at the speed of 30\%-40\% that is $10 \%$ higher than tourism overall development speed, China's tourism total revenue was over 880 billion Yuan in 2006, from which sports tourism, entertainment tourism revenue occupied nearly 1/3." It indicates that sports tourism accounts for more and more proportions in Chinese tourism and sports industry, especially for Beijing Olympic Games hosting in 2008, it even improves national sports participation consciousness, which provides good development opportunity for Chinese sport tourism development. Sports tourism has gradually become new highlight in public tourism, it attracts all levels' governments, investors and developers' attentions, and also attracts the eyes of scholars, is focused by theoretical circle (AN Chuan-yan 2014).

Research finds that domestic and international scholars haven't had unified language about the definition of "sports tourism", but all emphasize on sports activities importance in tourism process, 
and point out it should take sports resources as the foundation of holding sports tourism activities (YU Sumei 2005). Their differences mainly reflect in the expression of activity contents and forms, and most of them start from self-study perspective, so on the basis of formers research, if it can take logical starting point as tourism activities owned sports functions, or using tourists as main purposes or tourism main contents, writer think that sports tourism refers to a kind of tourism activity form that people rely on certain sports resources, take activities of sports significance as main purposes or main contents to meet and adapt to their all kinds of sports demands. Define it in this way can better handle the relations between sports and tourism that sports and tourism are mutual supplemented and closely related, sports in tourism process, tourism in sports activities that compose of whole contents of sports tourism, is objective existence that sports and tourism mutual correlate and act. Regarding sports tourism resources understanding and definition, the west generally call it as a joint name "tourist attraction" that refers to the sum total of all factors sightseeing places attract tourists, including corresponding reception services (Zhang Bing, Gao Song, Zhang Jianjun, Zeng Quanhong, Li Ming, 2013). According to "The People's Republic of China national standard (GB/18972-2003) tourism resources classification, investigation and evaluation", it defines tourism resources as all things and factors that nature and human society can attract tourists' attention, can be explored and utilized by tourism, and can generate economic effectiveness, social effectiveness and environment effectiveness (DENG et al. 2006). Through consulting relevant document literature, regarding sports tourism resources definition, by far its research results are fewer, current result mainly are some thoughts in tourism educational circle, basically no big ambiguity. Sports tourism resources in a broad sense, it should be sports tourism product tourism resources that can be available for exploring, including sports things and sports phenomena that possess tourism attraction potential as well as sports activities carriers that offer service to different places visitors, sports tourism product development raw materials and so on (AN Zhong-pei 2005).

Sports tourism as a new field that tourism and sports industry cross, it is still in the beginning development stage in China, some Chinese scholars have done several researches on sports tourism development, but according to document literature that I consult, domestic scholars researches started later, they haven't yet formed into complete theory system, which wasn't of prevail guiding significance in regional sports tourism development, and sports tourism operational management engagement wasn't deeper (Zhu 2000). Therefore, present and future sports tourism practice development urgently needs to strengthen research in such field, especially for sports tourism resources basic theory, how to pursue a kind of resources development way that fits for sports tourism its own development to provide basic thoughts for tourism planning and construction, and put forward corresponding measures, which is of significance in a long-run in Chinese sports industry and tourism development. And a landscape treasure as Qichun, Hubei, it is rich in natural resources but until now there is no relative ideal and influential sports tourist attraction, so it is necessary to do systematic research on Qichun country sports resources development.

\section{RESEARCH OBJECTS AND METHODS}

\subsection{Research Objects}

The research takes sport tourist resources from Qichun country of Hubei province as research objects, it focuses on field visiting Caohe, Qizhou, Datong, Qingshi, Tongzi, Tanlin, Zhulin and other villages and towns.

\subsection{Research Methods}

Document literature: Widely consult and collect relevant document literature through school library and CNKI, then analyze and sort them to provide firm theoretical basis for the research.

Questionnaire survey: By questionnaire survey on Qichun country villages and towns' residents, Qichun country Global, The Master and other travel agencies, it further collects relevant data to do sorting and analysis.

Field visit method: Proceed with field visiting Qichun country, comprehensive comprehend Qichun country sports tourism resources distribution, quantity, type, features, existing problems and sports tourism infrastructure as well as other information to provide real and reliable basic information for the research.

Logical analysis method: In analyzing information process, it applies logic knowledge and methods to classify and compare, conclude and deduct, analyze and synthesize information, and carry out logical reasoning of relevant theories. 


\section{Processes And Analysis}

According to domestic and international experts and scholars' research results and the requirement of the research, the research defines sports tourism as the sum total of a kind of social economic activity and social cultural activity that tourists depend on all kinds of tourism resources and sports resources in tourism activities. The essence is a kind of behavior activity that going on by utilizing sports resources and tourism resources, the definition well reflects sports and tourism basic attributes. When we comprehend sports tourism, we should cast aside discipline affiliation and industry benefits disputes, the paper thinks that "tourist activity" and "sports activity" defined scope in "sports tourism" should be extensive, firstly, "tourist activity", according to modern tourism science expression of tourism concept; it is thought that it can be regarded as tourism as long as leaving daily life place and traveling for a certain distance. Time is constantly changing, connotation and extension of tourism is also changing accordingly, recent years' continuous development of "village tourism", "suburbs tourism" is best examples, various places organized sports tourism items in suburbs tourism also bring along a series of economic effectiveness. Secondly, "sports" understanding should cast aside the definition of sports in narrow sense, don't only restrict in traditional sports events range. Mountain climbing, fishing, walking, hot spring bath, picking fruits in mountains and plains as well as others have been included into sports tourism extension, contrasting to the essence of definition, these are also should be considered one kind of sports tourism. In such recognition, no matter how many proportion that tourism and sports are, or being passive participated or proactive participated, all can be recognized according to sports tourism, only distinguish it from daily sports fitness exercises is needed. In short, sports tourism resources are all activity places, items and material environment that provide for people to conduct sports and fitness tourism activities. Sports tourism resources always constantly change and develop with human material civilization and spiritual civilization progress. Therefore, only constantly explore new sports tourism resources types, enrich sports tourism activities contents then we can let sports tourism to gain continuous development.

\subsection{Sports Tourism Resources Development Contents and Theoretical Basis}

Sports tourism resources development is a kind of comprehensive work, generally it is thought that its main contents are aspects as following:

Sports tourism resources values and functions excavation: For undeveloped and potential sports tourism resources, it should excavate their tourism values and functions on the basis of site investigation, and do a good job in promotional marketing to attract tourists, and for utilized sports tourism resources, then it should focus on exploring their other available values and functions, improve the width and depth of their utilization.

Sports facilities and sports tourism service facilities construction: Sports tourism facilities construction includes relevant supporting facilities construction, sports buildings and necessary sports equipments and devices as well as sports tourism activities safety guarantee system. Sports tourism service facilities mainly include tourism restaurant, tourism agency, rest foundation and commercial service facilities and so on.

Sports tourist area planning and designing need to combine with the region sports tourism resources advantages, select sports tourism items that fit for local practical conditions to explore so that better give effectiveness that is brought by sports tourism resources into play.

Sports tourism professionals' cultivation: To attract large quantity of passengers, sports tourist attraction's service quality is crucial. And so it has certain requirements on working staff that goes in for sports tourism, except for certain professional technology that should be possessed, they also need good service attitudes.

Sports tourism information networks: Modern society has entered into network era for a long time; therefore sports tourism network information establishment needs a professional team with sports tourism information, and further forms into dynamic information service system.

One of important factors that contribute to sports tourism rapidly development in the world is beneficial to relevant theories research and guiding effects. Its basic theories mainly include tourism economics theory, location theory, tourist capacity theory, tourism system theory and sustainable development theory and so on. Guided by tourism economics theory, it can define best investment plan that uses minimum resources consumption and less capital investment to meet demands to maximum degree; apply tourism location principle and method, develop sports tourism resources, 
according to sport sports tourism resources locality and immovability, sports tourism resources values, features and territory, it defines sports tourism space organizational level and planning development level; sports tourism resources exploration should possess sustainable development thought, strengthen resources and environment protection consciousness so that let sports tourism exploration's all activities to be beneficial to human health and social progress.

\subsection{Hubei Province's Qichun Country Leisure Sports Tourism Resources Development Current Situation}

Qichun has beautiful waters and mysterious mountains, attractive scenery, and various natural area tourism resources. In view of geomorphologic landscape, Qichun internal Dabie Mountain height is averagely around 1500 meters, the developed scenes are Triangle mountain, Henggang mountain, Yundan mountain and Fairy Table mountain, the scenes types are complicated and diversified, climate and vegetation conditions are good, and also have plentiful humanistic ecological resources, which is suitable to organize mountaineering and hiking, summer vacation, exploration and novelty hunting, sports entertainment, ecological agriculture and other kinds of tourist activities. In view of water-body resources, Qichun country owns Qi River, Chidong Lake, Chixi Lake, Rain Lake, Tongzi hot spring, Triangle mountain waterfall and so on, which is suitable to hold rowing, fishing, swimming, drifting, water skiing, hot spring bathing and other sports tourist activities. And there are also some forest parks as Triangle Mountain national forest Park, Henggang Mountain national forest park, Taiping National Forest Park and other scenic spots that are available for people taking relaxation sports. Especially for Li Shizhen international health and cultural tourism development area, it will core to healthy culture, take relaxation holidays as modes, use entertainment sports as extension, and further form into layout of all parts that respectively functioning as entertainment sightseeing, experiencing tourism, sports rehabilitation and sightseeing tour. Such as "one spring (Tongzi hot spring) plate" with subject of "sports rehabilitation", it can establish hot spring vocational village and hold mountain bike cycling competition, mountain rock climbing and drifting as well as other sports competitive activities, combine them together to form into sports rehabilitation foundation with unique features, and also can build the plate into "sports rehabilitation foundation in national level". Furthermore, as "two mountains (Triangle mountain, Fairy Table mountain) plate" with subject of "entertainment sightseeing, experiencing tourism", it bases on sightseeing and entertainment in Triangle Mountain natural cultural scenic zone while bases on experiencing tourism in Fairy Table healthy ecological tea garden, passengers can have the pleasant experiences of tea planting, tea leaves picking, tea making and tea tasting in tea garden, and then build the plate into places of first choice in center China sightseeing entertainment, and tourism experiencing.

Fitness types of sports tourism resources: So far, the fitness types of sports tourism resources that have been developed in Qichun are hiking, natural hot spring bathing, middle and aged aerobics contests and other items( as Figure 1, Figure 2):

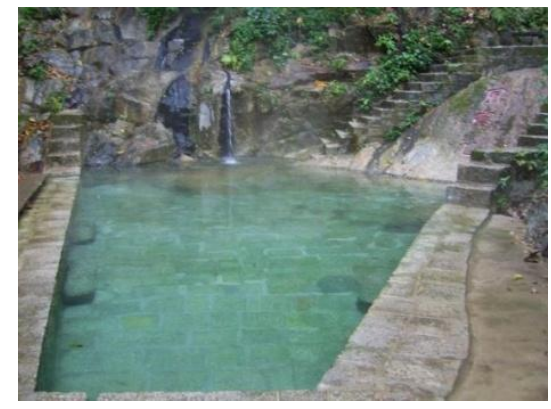

Figure1. Qichun Country Tongzi Hot Spring

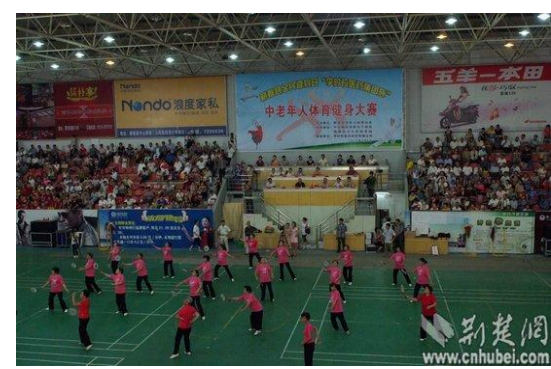

Figure2. Qichun Country Middle and Aged Sports Fitness Contest 
Tongzi hot spring locates in the Tongzi riverside of Qichun country. It has seven natural spring openings, daily average flow is 8191 tons, where is advantaged natural health maintenance bathing place since ancient times. It is distributed in Tangchi village east, west and north these three orientation, its flow is unevenly from over 10 tons per day to 68.6 tons per day, water temperature is between 24 and $42^{\circ} \mathrm{C}$, fluorine ion content is 2.5 to 8 milligram per liter, it can cure skin disease that is caused by lacking of fluorine, rheumatoid arthritis, rheumatic heart diseases and so on. After enjoying hot spring bathing, you can step up and climb to the top of Yundan Mountain, green mountains surround four sides and mountain villa as well as pavilions cover everywhere as far as the eyes can see. Taiping Lake's a puddle of water, clear and glittering that reflects the beauty of mountains and waters as well as thousands of weather. Zhengjia Mountain woods are luxuriant, modeling of dragon egg pit is peculiar, stone path is flat, the most beautiful thing is opening up pace to wander around .Along Dabie Mountain red tourism road, it enters into Qichun north part Bluestone Town, the Yundan Mountain scenic zone that gathers mountains, lakes, waterfalls, and hot spring while integrates beauty, strange, dangerous and unique, is conspicuous on show, throughout the journey, you can enjoy South Milky Way drifting, Medicine King Valley, Grand canyon with bottomless cliffs, Longxi waterfall and the Mountain of Flames.

In recent years, Qichun country also have held a series of national or international large-scale sports events (as Table 1), and yearly middle and aged sports fitness competition that is jointly hosted by Qichun country middle and aged sports association, Qichun country senior cadres bureau and Qichun country style council as well as co-organized by Li Shizhen Medicine Group, which provides good fitness place and exhibition platform for visitors and Qichun country's people. "I am healthy, and I am happy" have already become spiritual connotation in whole country's masses new life.

Table1. Qichun Country Recent Three Years Hosted Sports Competitions

\begin{tabular}{|c|c|}
\hline Time & Event \\
\hline 2012 & Nationwide automobile site cross-country championships Qichun station \\
\hline \multirow{3}{*}{2013} & \begin{tabular}{|lllllll}
$\begin{array}{c}\text { "Agly Cup" Hubei province' } \\
\text { championships }\end{array}$ & Qichun nationwide automobile site cross-country \\
\end{tabular} \\
\hline & Qichun fist session of square dance fitness dance competition \\
\hline & Middle and aged sports fitness competition \\
\hline 2014 & May 1st "Price Cup" table tennis sports meeting \\
\hline
\end{tabular}

From above Table 1, it is clear that Qichun country sports competitions are mainly sightseeing and fitness types of exercises but popularity is not high and have no features, for these problems, it gets following conclusions by investigation, first is capital shortage, some sports events hosting needs lots of funds, but investment emphasis is not in sports competition tourism resources development, competition units that are responsible for holding tend to be powerless and then economic effectiveness reduces. Second is competition events professional is too strong, people that are interested in these events are few, emphasis of people leisure time is on amateur entertainment rather than these sports events, the participation is greatly reduced. Third is insufficient publicity, local residents have no comprehensive understanding on Qichun country fixed sports tourism resources, while is little for external visitors.

By investigating on Qichun country sports tourism resources, referencing statistical results of how many Qichun country sports tourist attractions is known, it is clear that one sports tourist attraction awareness rate occupies 8\%, two sports tourist attractions awareness rate occupies 63\%, and three sports tourist attractions awareness rate occupies $25 \%$, while over four sports tourist attractions awareness rate only occupies $4 \%$. Thereupon, Qichun country sports tourism resources impacts and popularity in society is not high enough, no matter for external visitors or local visitors, all know little about Qichun country sports tourist attraction, which shows Qichun country hasn't yet formed into good sports tourism atmosphere, and it should strengthen publicity.

Stimulation types of sports tourism resources: By far, Qichun developed stimulation types of sports tourism resources are drifting, passing through canyon, prompt dropping cliff, stream climbing, bouncing deep pool, falling waterfall and other events (as Figure 3, 4), but these sports tourism resources haven't yet widespread developed, only little outdoors sports enthusiasts would play such games, due to high dangerousness, the type of resources accordingly have been ignored, but development prospect is still very broad. 


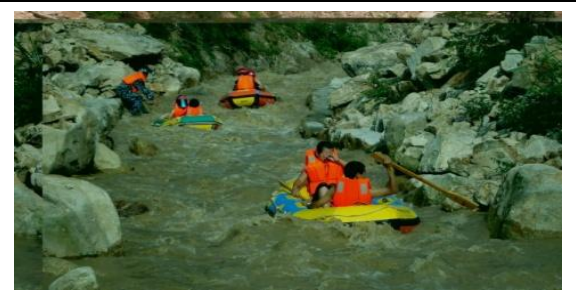

Figure3. Qichun Country South Milky Way Drifting

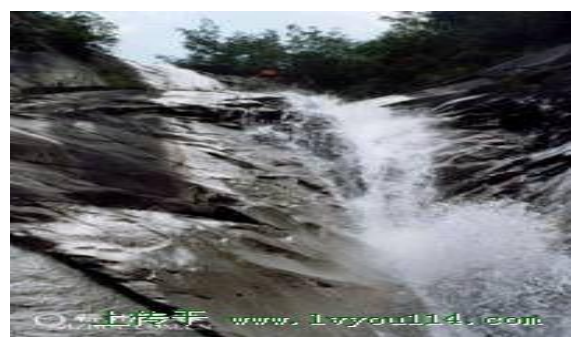

Figure4. Qichun Country Medicine King Valley Waterfall Falling

South Milky Way drifting scenic zone locates in Qichun country's Bluestone town, together with neighboring Taiping mountain villa summer resort, Tongzi hot spring relaxation, Medicine King Valley stream climbing, Wuma village exploration, White Cloud hole clouds viewing and others compose to an original ecological scenic zone that integrates relaxation, vacation spending, drifting and exploration. The full length of river way is nearly 4 kilometers; drifting time is one and a half hours. South Milky Way is the prototype of Tongtian River in Wu Cheng-en "Pilgrimage to the West", riding by rubber boat along cliffs and going downstairs, the sky is high and water is long, sun is shining over all the earth, green hills surround in all direction, drifting among them and you will find out a kind of rare excitement, a kind of unique feeling that is different from ordinary life in busy city life. Qichun is hometown of medical sage Li ShiZhen, where still kept lots of traditional ways of health care, especially was famous for medicated diet, medicated bath and so on, along with successful development of drifting, it let "medical sage hometown healthy cultural traveling" to be more perfect.

Grand canyon with bottomless cliffs belongs to Dabie Mountain range, it locates in the south wing of Dabie Mountain, where lies in Qichun country Taiping summer resort, altitude of the peak is $1244.2 \mathrm{~m}$, mountain sharp drops and inclines from northeast to southwest, is exactly like the great dragon that is the highest in Qichun country, mountain highest temperature in middle summer is around $28^{\circ} \mathrm{C}$ centigrade, humidity is small without mosquitoes. Overlook brooks and waterfalls, strange stones and queer rocks are everywhere, stream is always flowing in a whole year, where has a feeling of land of idyllic beauty. For most of outdoors brook falling players, the Grand Canyon with bottomless cliffs is still a valley of no reputation. Common people only can overlook the valley in the opposite direction, highly praise its winding and beauty, while never have the opportunity to get close to see it. On one hand, it is because the grand canyon with bottomless cliffs, ravines are deep and no path here, is a undeveloped place that no one set foot; on the other hand, its precipice is steep and covered by bushy shrubs and luxuriant weeds, it hides frightened highly toxic long-noded pit viper among wood and grass, enormous risks and growing crisis exist in every steps. At present, there are some clubs that work on introducing and exploring brook falling activity, the event organization is little at home, but travelers can go to mountain stream and brook to experience its stimulation and enjoyment.

Watching types of sports tourism resources: Qichun country sightseeing types of sports tourism resources are rather rich, now the developed ones are Li Shi-Zhen cemetery, Qizhou studio city, automobile site cross-country championships, cultural square and so on(as Figure 5-8):

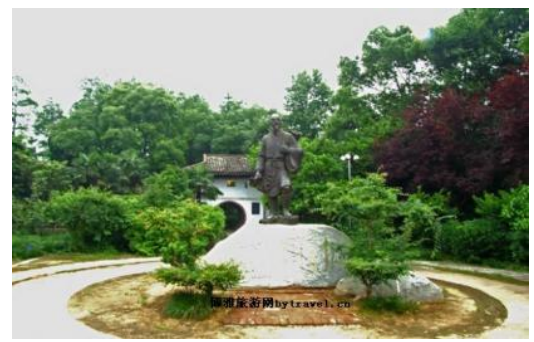

Figure5. Qichun Country Li Shi-Zhen Cemetery 


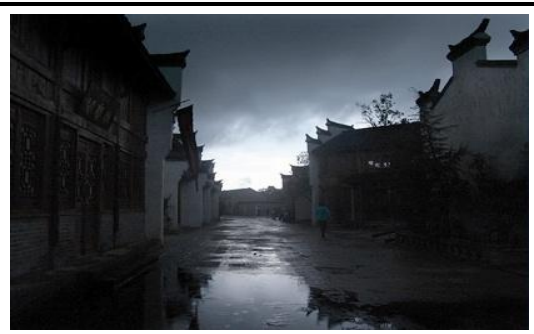

Figure6. Qichun Country Qizhou Studio City

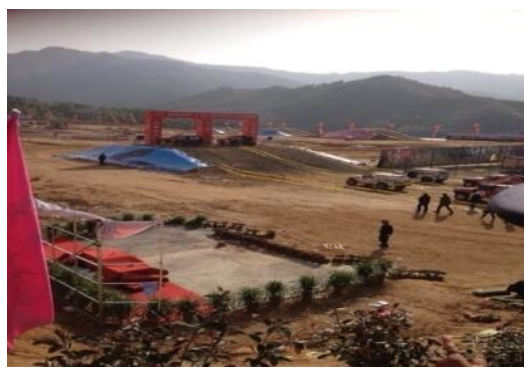

Figure7. Qichun Country Automobile Site Cross-Field Championships

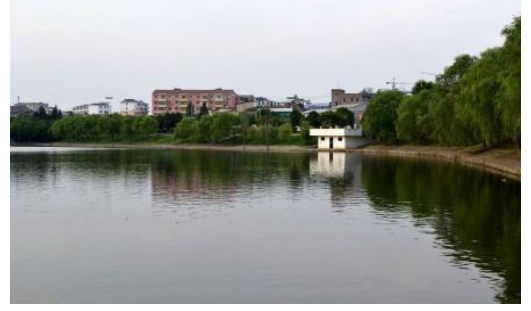

Figure8. Qichun Country Cultural Square

Li Shi-Zhen cemetery lies in the shore of beautiful scenic Rain Lake of Qizhou southeast, it covers an area of 80mu, which is composed of Li Shi-Zhen cemetery, Li Shi-Zhen memorial hall, Li Shi-Zhen medical history literature library and medicine garden four parts, is national key cultural relics protection unit. Memorial hall name is inscribed by comrade Deng Xiao-Ping, is architectural complex in ancient style in China(Ming Dynasty), quite splendid, well-proportioned, the engineering obtains "Luban Awards", treasures domestic and international over ten kinds of "Compendium of Materia Medica" inside hall, and medical books, document literature and newspapers as well as periodicals that introduce Li Shi-Zhen at all times and in all over the world. And meanwhile it also is demonstration base of national patriotism education, which listed into "Qiyang eight views" in the ancient times, Li Shi-Zhen and his son's original tombs and tombstone have been well preserved until now. Li Shi-Zhen medicine garden includes medicine stele corridor and Baicao garden two parts, which is Chinese first traditional Chinese medicine museum of Natural History. Chinese material medica inscription gallery inlays 128 pieces of medicine stone carving, carving is exquisite and true to life; Baicao garden plants over 310 varieties of medicines. Li Shi-Zhen cemetery, since it opened up in April, 1981, averagely received over 40 ten thousand Chinese and foreign visitors per year.

Studio city lies in the north side of Pan Gulf the south terminal of Red Dragon Lake of Qichun country, and is imitated as shooting base of soap opera "Ming Dynasty Medical Sage Li Shi-Zhen". Studio city gets close to high speed life service station, its south side relates to former residence of $\mathrm{Li}$ Shi-Zhen, is a community sub center that integrated entertainment culture and tourism, as Ming Dynasty cultural tourist attraction in post period, the whole ancient city just like preserved historical site and also land of idyllic beauty. Studio city's markets and streets focus on modern utilization of ancient elements, which can meet visitors sightseeing demands on ancient cities and ancient streets, and also meet the demands of visitors relaxation and vacation spending that combines with Chinese medicine principles of "Compendium of Materia Medica", holds various health maintenance and physical therapies items as medicated diet, medicated bath and medicine foot massage as well as others, visitors can go deeper to experience. As a big scenic spot in Red Dragon Lake international health tourism relaxation holiday resort, studio city lies among Red Dragon Lake and Li Shi-Zhen memorial hall as well as Rain Lake, which plays well connection roles, such landscape series connects 
with Li Shi-Zhen former residence humanistic history surely will generate sensational effects and then propel to interactive development, such development also greatly propel and perfect whole Qichun country environment.

Leisure types of sports tourism resources: By far, Qichun country developed recreational types of sports tourism resources are mountain climbing, rowing, fishing, badminton, golf, square dance and other events(as Figure 9- Figure 10):

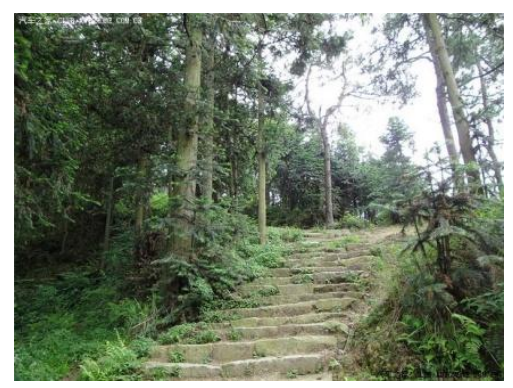

Figure9. Qichun Country Henggang Mountain Climbing

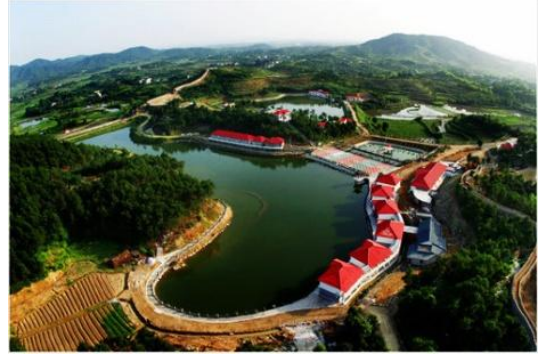

Figure10. Qichun Country Tam Giang Resort And Spa

Qichun country's Henggang Mountain lies in the junction of Hubei province Qichun and Wuxue. Peaks rising one after another, just like dragon sleeps in its mountain peak so is named as "Henggang". The peak is 815 meters, it has long been known as shield of east area of Hubei province, Henggang mountain has deep woods and tall bamboos, which grow greener and fresher, Dynasty Sui and Tang cut into mountain, temples stand everywhere, scenic spots are quite a lot and concentrated, Henggang mountain being highly erected and green that is one of ten scenes, approved by provincial nationality and religious bureau in 1988, it formally opened Buddhist and temple activities. It founded "Henggang mountain forest park" by the approval of the ministry of forestry in 1992, which became famous mountain and scenic spot in adjoined provinces, countries (cities) religious activities and tourism. Yearly passengers are 20 ten thousand people. Henggang mountain built its unique tourism advantages with its splendid forest overall landscape, beautiful natural scenery and its long-standing religious origins, famous humanistic historical site, grand temple architecture, superior geographic and traffic positions. Temple scenes are Zhenwu palace, Goddess palace, Ancestors father palace, Jade Emperor palace and Temple cloud cover. Henggang mountain temples initially established in the beginning of Dynasty Sui, Zen's fourth ancestor Simadaoxin had ever became a monk in childhood in seventh year of Zuoxi. When practiced in those years, stonewall left fingerprints and stone bench, stone chair, stone house have existed up to now. In the period of Dynasty Tang and Song, Buddism and Taoism were unified, Buddhist temples and Taoist abbey were in full flourish, air is fresh inside scenic zone, weather is cooling, which is specially fit for visitors mountain climbing exercising. Qichun country Tam Giang ecological tourist resort is national scenic spot in AAA level, is surrounded by mountains and girdled by a river, environment is beautiful, forms into all kinds of microenvironment, has regions of broad visions that faces to lakes and behind mountains, quiet and secluded districts in the top that thick forest surrounds, gentle slopes with its lake ends close to mountain, fruit areas with rich countryside flavors of its own style, residential areas with bamboo forest surrounding, sceneries are different, which provides extreme good conditions for creating ecological vacation resort colorful experience space.

By investigation and analysis of Qichun country sports tourism resources, it can classify Qichun country sports tourist products into following four types: fitness type, stimulation type, watching type, and leisure type. Qichun country sports tourism resources development product types selection can reference questionnaire survey's visitors such problems interests answers statistical results, statistical 
result (Figure11) shows that fitness type's proportion is the largest that arrives at $42 \%$; secondly is watching type that accounts for 30\%; and then is leisure type that accounts for 19\%; And finally is stimulation type that accounts for 9\%. To sum up, and combine with Qichun country sports tourism resources features, selection of Qichun country sports tourism resources development products types should be major in fitness and watching types, and concurrently develop leisure type and stimulation type.

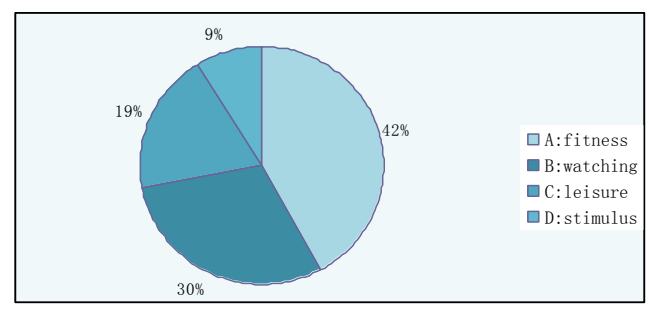

Figure11. Qichun Country Sports Tourist Items Passenger Interests' Investigation Statistical Figure

\subsection{Countermeasures to Leisure Sports Tourism Resources Development of Qichun Country, Hubei Province}

\section{1) Product Optimal Configuration, Brand Characteristics Highlighting}

By far, Qichun country sports tourism mostly rests on the level of viewing natural scenery and humanistic features and other views, except for drifting, fitness dance competition, participated items are fewer, while rural culture, hiking and exploration as well as other tourism forms of plentiful connotations haven't yet attracted attentions, developed tourism products are single, lacking of characteristics, owned local features memorial types are fewer, developed breadth and depth are not enough, its produced product packing also is not generous enough, product effectiveness is low. Each scenic spot carries out individual combat and has no personal features, external visitors' duration of stay in scenic spot is short, and local residents' positivity to scenic spot tourism is also not high enough. Though Qichun country has Li Shi-Zhen such world famous person as signboard, people that really understand its cultural connotation is little.

Therefore Qichun country sports tourism resources development should focus on developing advantageous resources, and further form into sports tourism brand with Qichun country features, for example through deeper excavating Li Shi-Zhen medical cultural connotation, combining with sports tourism resources, systematically well planning the two, developing all kinds of health maintenance tourism products, which lets visitors feel medical culture while also experience fitness and heart nourishing; build Li Shi-Zhen medical cultural brand and then let Chichun to become authority tourism country that represents Li Shi-Zhen culture. And meanwhile developer should do a good job in market segmentation, adopt different development measures and promotional ways as well as release different sports tourism products according to different groups of people at all ages. Besides, sports tourism resources development should also consider participants universality and hierarchy, different types of tourists have different requirements on sports tourism products, such as for the youth, it can develop rock climbing, bungee jumping, drifting and other events with challenge; for middle-aged people, it can develop mountain climbing, fishing, hot spring bathing, golf and other leisure events.

\section{2) Integrate all Kinds of Resources, Improve Resources Attraction}

Qichun country sports tourism resources development, though it attracts attention of country government, sports council and tourist administration to a certain degree, it lacks of deepen comprehensive investigation and comprehensive scientific evaluating argument, the development blindly follows, only focuses on scale, doesn't striving for quality, some scenic spots implement decentralized operation and repeated construction, such as Tam Giang Resort and Spa as well as Hubei provincial valley, resource development form is single, and level is not high, grade is not enough while feature is not strong so that lacks of attraction to customer market, and it is hard to form into accumulative effect and scale effects. Such extensive operation way forms into vicious circle of disregarding management and low quality that seriously restricts Qichun country sports tourism development.

Therefore, in order to stand out and improve its resources attraction, it need to ally with other tourism resources, integrate resources advantages, as combine rural tourism with sports tourism to develop, 
fully give the two kinds of tourism resources charms into play, ingenious fuse village beautiful natural scenes, rustic folk custom and national conditions as well as agriculture ecology landscape into sports tourist activities, let visitors to enjoy visual beauty, obtain physical and psychological pleasure and return to nature while also strengthen physique and feel the pleasure of sports. The combination surely can let sports tourist activities to be more attractive, and let sports tourism resources value to gain maximum reflection.

\section{3) Investment Introduction, Channels Diversified}

All tourism resources development needs certain investment, and Qichun country tourist area still belongs to undeveloped area, it should develop scenic spot road, telecommunications and other infrastructure if it wants to develop sports tourism resources, which needs sponsorship and investment from enterprises and developers, and coordination and lots of funding support from all walks of life, especially for Qichun country sports industry and tourism practitioners' coordination and cooperation. However, due to limited local fiscal capacity, it surely will not enough if only rely on government strength, while emphasis of investment is not in sports tourist event, so that no powerful investment subject to support, therefore in order to fill funding gaps of Qichun country sports tourism resources development, it should strengthen government guiding, transform investment system, break through regional and industrial limitation and use various ways and diversified channels to introduce investment on the premise that not go against natural law and according to the principle of more pay for more investment.

\section{4) Perfect Management System, Improve Service Quality}

Due to Qichun country sports tourism resources development and research is still in the lower level, operational management personnel for sports tourism is also relative little, management system is also imperfect, some management staff in practical tourism on-site operation is undertaken by local villagers, while local residents cultural quality generally is lower, they tend to lack of necessary tourist knowledge and relevant environment protection awareness, let alone corresponding professional technology so that leads to services quality to be poor, tourism operators quality is also not high, some restaurants and hotels waste water are let out everywhere, which leaves extremely bad impression to visitors.

And meanwhile by investigation on Qichun country institutions of higher education, they find that by far the institutions of higher education in Qichun country has not yet got involved in sports tourism major, and sports tourism professionals are important factors in sports tourism resources development, so institutions of higher education should increase sports tourism major in good time, cultivate sports tourism high quality professionals so that provide talents guarantee for Qichun country sports tourism sustainable development, of course, it can also bring into external high quality sports tourism professionals.

\section{5) Perfect Infrastructure, Expand Scale and Increase Propaganda}

Due to lots of foreign merchants development on real estate market, it further drives Qichun country economic rapidly development, however sports tourism market standstills, due to tourist spots are mostly in mountain area, relative isolated environment lets rural residents hygiene concepts to be backward, cultural quality to be lower, some fixed diet and hygiene practices to be hard to change, such as drinking and toilet as well as others' hygiene conditions are poor. Some scenic sports roads are in ruins, even are still puddle, which restricts sports tourism resources development. Therefore, it is necessary to exert to improve sports tourism infrastructure, and expand scale.

By field investigation, it is found that some external visitors even local residents lack of deepen comprehensive understanding on the country fixed sports tourism resources, which causes that resources utilization rate is not high, sports tourism market maximum effectiveness is not yet exerted, so it is necessary to strengthen propaganda and promotional marketing activities so that solicit more visitors.

\section{6) Intensify Safety Consciousness, Improve Guarantee}

Some stimulation types of sports tourism events bring us fresh and stimulated sports while also have certain hidden danger, as drifting, exploration, canyoning these sports tourism events themselves have certain dangerousness, so relevant departments, working staff should regularly hold sports tourism safety major inspection, conduct serious inspection on sports fields, all kinds of equipments and 
facilities and others so that reduce accident potential to minimum. For example, in South Milky Way drifting notice, it should mark relative public sign to warn visitors not to be panic if coming across danger, and meanwhile it also should equip with necessary medical aid facilities and medicines, and also strengthen visitors' insurance purchasing awareness in sports tourism process.

\section{Conclusion}

Qichun country has plentiful natural resources and long-standing historical and cultural heritage, which provides material and cultural foundation for sports tourism products development; however, due to sports tourism resources development theory being backward, some resources suffer restriction of regional and economic conditions that leads to small development scale and lack of features. By field investigation, the research classifies Chichun country sports tourism resources from different perspectives, according to sports tourism resources specialty, it classifies into fitness type, stimulation type, watching type and leisure type such four types; according to sports tourism resources development extent, it classifies into developed or to be developed sports tourism resources as well as undeveloped or potential sports tourism resources these two kinds.

By investigation and analysis of Qichun country sports tourism resources and tourist products, it can classify Qichun country sports tourist products into following four types: fitness type, stimulation type, watching type and leisure type. Result indicates that Qichun country sports tourist products development selection should base on fitness type and watching type, other types products can concurrently develop. Combining with Qichun country sports tourism resources current situation as well as sports tourism market consumption level and visitors consumption psychology, it puts forward product optimization allocation, brand features highlighting; all kinds of resources integration, and resources attraction improvement; investment introduction channel diversified; management system perfection, service quality improvement; infrastructure perfection, scale expansion and propaganda increasing; safety consciousness strengthening and guarantee enhancing as well as other development measures.

Develop sports tourism resources not only should consider social economic effectiveness, but also should focus on environment protection, fully excavate sports culture and tourism culture's connotations while also should combine with local villages and towns tourism resources advantages, regional conditions and economic development capacity to do comprehensive overall planning, and also objective analyze people revenue level, inner demands and consumption structure, and further correct evaluate market and develop different sports tourism events, besides, it can also use proactive and targeted marketing strategies to increase passengers quantity and improve passengers consumption level, and further avoid blindly following, repeat developing so that construct cultural Qichun, characteristic Qichun.

Develop sports tourism resources should be country government-oriented, regard enterprises and developers as subjects, strengthen Qichun country sports tourism market construction, integrate multiple tourism resources, form into sports tourism circle, build Li Shi-Zhen featured brands, attract the eyes of consumers, and further increase visitors sojourn time. Sports tourism resources development funds raising channels should be diversified, implement principle of "more pay for more investment", operational ways should be flexible, scope also should be extensive, and then form into situation that whole country people run sports tourism, push the country economy rapidly development.

\section{ACKNOWLEDGMENT}

State general administration of sports philosophy and social sciences research project: Based on "Internet+" the sport and tourism integration development path of research (Grand No. 2322SS16059).

\section{REFERENCES}

AN Chuan-yan 2014. Some thoughts on Engel coefficient, the Tourism Engels coefficient. Journal of Nanyang Teachers College, (6):49-52.

DENG Feng-lian, YU Su-mei, WU Sheng-qi 2006. Supportive System and Influential Factors of Exploitation of Sports Tourism Resources in Our Country. Journal of Shanghai Physical Education Institute, 30(2):35-40.

HAN Zhong-pei 2005. Research of Promotion Strategy in Sports Tourism. Journal of Xi'an Institute of Physical Education, 22(3):35-38. 
TAN Bai ying, ZOU Rong 2002. Development of the sport tourism in China. Journal of Physical Education, 9(3):22-25.

WANG Ju-hai 2012. The Analysis and Research of the Sports Tourism Market Based on Tourists Characteristics. Journal of Weinan Teachers College, (6):88-91.

YAN Shuren 2012. Analysis of the Sports Tourism Resources of Urban Agglomeration and the Strategy on Marketing Development. Journal of Shenyang Sport University, 31(1):34-37.

YU Sumei 2005.Study on Connotation and Development about the Resource of Sports Tourism. Journal of Chengdu Physical Education Institute, 31(1):26-28.

Zhang Bing, Gao Song, Zhang Jianjun, Zeng Quanhong, Li Ming, 2013, The competitiveness evaluation and empirical research of sports tourism industry for China's city. International Journal of Applied Mathematics and Statistics, 51(21):293-300.

Zhang Bing, Shi Zhengkai, Yu Libin, Jiang Weiqi, Tian Miao, Liu, Lu, 2014, Dabie mountain sports tourism project development location problems research under growth pole theory perspective. Journal of Chemical and Pharmaceutical Research, 6(6):460-464.

Zhu Jingmei 2000. Problems in Developing Sports Tourist Projects. Sports \& Science, 21(2):25-27.

\section{AUTHORS' BIOGRAPHY}

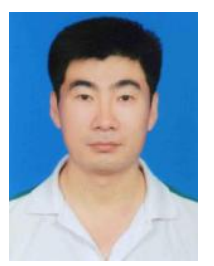

Corresponding Author: Bing Zhang(1973-), male, Mongolian, liaoning chaoyang, master degree, associate professor, research interests: sports industry and sports engineering, sports management. Address: No. 146, Xingang 2 Road, Huanggang City, Hubei Province, P.R.China (Institute of Physical Education, Huanggang Normal University); Zip code: 438000; Email: tiyuxi@qq.com.

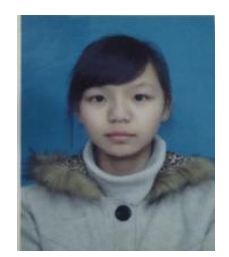

Qian Yang (1996-), female, the Han nationality, hubei wuhan, undergraduate degree, research assistant, Institute of Physical Education Huanggang Normal University grade 2014students; research interests: sports industry and sports engineering, sports management.

Xiao HONG, female, QiChun, Institute of Physical Education Huanggang Normal University grade 2010 students; Methods: the sports industry and sports education. 